\title{
Childhood maltreatment and metabolic syndrome in bipolar disorders: in search of
}

\section{moderators}

Ophelia Godin ${ }^{1,2}$, Géraud Gaube ${ }^{3}$, Emilie Olié ${ }^{1,6}$, Raoul Belzeaux ${ }^{1,5}$, Frank Bellivier ${ }^{1,14}$, Joséphine Loftus ${ }^{1,10}$, Philippe Courtet ${ }^{1,6}$, Caroline Dubertret ${ }^{1,7}$, Pierre-Michel llorca ${ }^{1,13}$, Sebastien Gard ${ }^{1,4}$, Chantal Henry ${ }^{8}$, Raymund Schwan ${ }^{1,9}$, Christine Passerieux ${ }^{1,11}$, Mircea Polosan ${ }^{1,12}$, Ludovic Samalin ${ }^{1,13}$, FondaMental Advanced Centers of Expertise in Bipolar Disorders (FACE-BD) Collaborators ${ }^{*}$, Marion Leboyer ${ }^{1,2}$, Bruno Etain ${ }^{1,14}$

1. Fondation FondaMental, Créteil, France;

2. Univ Paris Est Créteil, INSERM, IMRB, Translational Neuropsychiatry, AP-HP, DMU IMPACT, FHU ADAPT, Fondation FondaMental, F-94010, Créteil, France

3. APHP. Sorbonne Université, Département Medico-Universitaire Neurosciences, Unité de Psychiatrie, Psychotraumatologie et Addictions, Hôpital Tenon, Paris, France;

4. Centre Expert Troubles Bipolaires, Service de Psychiatrie Adulte, Hôpital Charles-Perrens, Bordeaux, France;

5. Pôle de Psychiatrie, Assistance Publique Hôpitaux de Marseille, Marseille, France; INTUMR7289, CNRS Aix-Marseille Université, Marseille, France;

6. Department of Emergency Psychiatry and Acute Care, Lapeyronie Hospital, CHU Montpellier, Montpellier, France; PSNREC, Univ Montpellier, INSERM, CHU Montpellier, Montpellier, France;

7. AP-HP, Groupe Hospitalo-universitaire Nord, DMU ESPRIT, service de Psychiatrie et Addictologie. Hopital Louis Mourier, Colombes, Inserm U1266, Faculté de médecine, Université de Paris, France;

8. Department of Psychiatry, Service Hospitalo-Universitaire, GHU Paris Psychiatrie \& Neuroscience, F-75014, Paris, France;

9. Université de Lorraine, Inserm U1114, Centre Psychothérapique de Nancy, Nancy, France;

10. Pôle de Psychiatrie, Centre Hospitalier Princesse Grace, Monaco, France;

11. Service Universitaire de Psychiatrie d'Adultes, Centre Hospitalier de Versailles, Le Chesnay, Service Universitaire de Psychiatrie d'Adultes, Centre Hospitalier de Versailles, Le Chesnay,Université Paris-Saclay, UVSQ, Inserm, CESP, Team "DevPsy", 94807, Villejuif, France;

12. Université Grenoble Alpes, CHU de Grenoble et des Alpes, Grenoble Institut des Neurosciences (GIN) Inserm U 1216, Grenoble, France; 
13. CHU Clermont-Ferrand, Department of Psychiatry, University of Clermont Auvergne, EA7280, Clermont-Ferrand, France;

14. Assistance Publique des Hôpitaux de Paris (AP-HP) Paris.Nord, GHU Saint-Louis Lariboisière - Fernand Widal, DMU Neurosciences, Département de Psychiatrie et de Médecine Addictologique, INSERM UMRS 1144, Université de Paris, Paris, France.

*List of FondaMental Advanced Center of Expertise (FACE-BD) collaborators:

FACE-BD Clinical Coordinating Center (Fondation FondaMental): B. Etain, C. Henry, E.

Olié, M. Leboyer, E. Haffen and PM Llorca;

FACE-BD Data Coordinating Center (Fondation FondaMental): V. Barteau, S. Bensalem, O.

Godin, H. Laouamri, and K. Souryis;

FACE-BD Clinical Sites and Principal Collaborators in France;

AP-HP, DHU PePSY, Pôle de Psychiatrie et d'Addictologie des Hôpitaux Universitaires H

Mondor, Créteil: S. Hotier, A. Pelletier, N. Drancourt, JP. Sanchez, E. Saliou, C. Hebbache, J.

Petrucci, L. Willaume and E. Bourdin;

AP-HP, GH Saint-Louis-Lariboisière-Fernand Widal, Pôle Neurosciences, Paris: F. Bellivier, M. Carminati, B. Etain, E. Marlinge, J. Meheust, M. Meyrel;

Hôpital C. Perrens, Centre Expert Trouble Bipolaire, Service de Psychiatrie Adulte, Pôle 3-47, Bordeaux: B. Aouizerate, A. Desage, S. Gard, J Sportich, K. Mbailara, I. Minois, and L.

Zanouy;

Département d'Urgence et Post Urgence Psychiatrique, CHRU Montpellier, Montpellier: L.

Bardin, A. Cazals, P. Courtet, B. Deffinis, D. Ducasse, M. Gachet, A. Henrion, F. Molière, B.

Noisette, E. Olié and G. Tarquini;

Pôle de Psychiatrie, addictologie et pédopsychiatrie, Hôpital Sainte Marguerite, Marseille: R. Belzeaux, N. Correard, F. Groppi, A. Lefrere, L. Lescalier., E. Moreau, J. Pastol, M. Rebattu, B. Roux and N. Viglianese;

Service de Psychiatrie et Psychologie Clinique, CHU de Nancy, Hôpitaux de Brabois, Vandoeuvre Les Nancy: R. Cohen, Raymond Schwan, J.P. Kahn, M. Milazzo, and O.

Wajsbrot-Elgrabli;

Service Universitaire de Psychiatrie, CHU de Grenoble et des Alpes, Grenoble: T. Bougerol,

B. Fredembach, A. Suisse, B. Halili, A Pouchon, and M. Polosan

Centre Hospitalier de Versailles, Service Universitaire de Psychiatrie d'adultes, Le Chesnay:

A.M. Galliot, I. Grévin, A.S. Cannavo, N. Kayser, C. Passerieux, and P. Roux; Service de Psychiatrie,

Service de Psychiatrie Centre Hospitalier Princesse Grace, Monaco: V. Aubin, I. Cussac, M.A Dupont, J. Loftus, and I. Medecin ;

Service de psychiatrie et addictologie, Hôpital Louis Mourier, Colombes, AP-HP Nord,

France : C. Dubertret, N. Mazer, C. Portalier, C. Scognamiglio, A. Bing.

\section{Corresponding Author}

Ophélia Godin

Fondation FondaMental

Hopital Albert Chenevier, Pôle de Psychiatrie, 40 rue de Mesly, 94010 Creteil Cedex

(Tel: +33 142162546, Fax: +33 149813456,

e-mail: ophelia.godin@fondation-fondamental.org 


\section{Abstract}

As compared to the general population, adult individuals with bipolar disorders (BD) have higher mortality rates due to cardiovascular diseases and higher prevalence of Metabolic Syndrome (MetS). Recent evidence suggests that childhood maltreatment may contribute to the cardiovascular burden in individuals with BD. However, studies are scarce, with limited sample sizes and inconsistent results. We explored the associations between a self-reported history of childhood maltreatment and MetS (and its subcomponents) in a large sample of 2390 individuals with BD. Childhood maltreatment was assessed using the Childhood Trauma Questionnaire and MetS was defined according to the revised criteria of the ATEP III. We suggested associations between childhood maltreatment and the presence of MetS in men and in younger individuals. The association between childhood maltreatment and the presence of MetS in the early onset subgroup was not significant after adjustment for site of recruitment and level of education. Hence, some links between childhood maltreatment and MetS might exist only in specific subgroups of individuals with $\mathrm{BD}$, but confirmation is required in independent and large samples, while taking into account potential confounders. This would help defining how psychosocial interventions that target childhood maltreatment and its consequences may be beneficial for physical health.

Keyword: bipolar disorders; childhood trauma; childhood maltreatment; metabolic syndrome; metabolic abnormalities; CRP 


\section{Introduction}

As compared to the general population, individuals with bipolar disorders (BD) are at higher risk of premature death, this being not exclusively related to suicide. Life expectancy has been estimated to be 10 to 15 years shorter for individuals with BD (Roshanaei-Moghaddam and Katon, 2009). As compared to the general population, mortality rates due to physical causes (mainly cardiovascular diseases (CVD)) are between 1.5 and 3 times higher in adults with $\mathrm{BD}$, as compared to the general population (Management of Physical Health Conditions in Adults with Severe Mental Disorders, 2018).

Metabolic syndrome (MetS) is recognized as a leading cause of CVD-related mortality in the general population. MetS is highly prevalent in $\mathrm{BD}$, with an estimated global rate of $32.6 \%$, that is two times higher than the rate observed in the general population (Vancampfort et al., 2015). Most common interpretations of this cardiovascular burden in BD are : unhealthy lifestyle (sedentary behaviour, harmful use of tobacco, alcohol and illicit drugs), exposure to psychotropic drugs that can induce MetS and a possible genetic overlap between BD and several somatic conditions, including inflammatory conditions (Leboyer et al., 2012). Recent evidence also suggests that childhood maltreatment is a plausible explanation of this greater cardiovascular burden in individuals with BD (Hughes et al., 2017; Quidé et al., 2020). However, the results in the literature are scarce with a few studies, all performed in limited sample sizes and with inconsistent results (Aas et al., 2017; Hosang et al., 2018; Leclerc et al., 2018; McIntyre et al., 2012).

The aim of this study was therefore to test for the associations between MetS and a selfreported history of childhood maltreatment in a large sample of 2390 individuals with BD. 


\section{Material and methods}

\section{Study Population}

Individuals were recruited in 12 Centers of Expertise for BD that used the same systematic and standardized clinical assessments. All individuals were stabilized outpatients who were aged 16 years or older, diagnosed with BD (subtypes I, II, and not otherwise specified) according to DSM-IV criteria (American Psychiatric Association, 1994). This cohort have been described in details in previous articles (Henry et al., 2015). Clinical stabilization was defined as the absence of hospitalization and treatment modifications in the 4 weeks before inclusion (but not by the absence of any mood symptoms).

The assessment protocol was approved by the institutional review board (Comite de Protection des Personnes Ile de France IX; January 18, 2010), in accordance with the French laws for non-interventional studies and requires only an information letter for participation.

\section{Clinical assessment}

At inclusion, a specialized team (psychiatrist and psychologist) interviewed the individuals using the SCID (First, 1996) and systematically recorded information about education, marital status, onset and course of BD and psychiatric and somatic comorbidities. Current depressive and hypomanic symptoms were assessed respectively with the Montgomery Asberg Depression Rating Scale and the Young Mania Rating Scale. Childhood maltreatment was assessed using the Childhood Trauma Questionnaire (CTQ) (Bernstein et al., 2003). The CTQ is a 28 -item self-report questionnaire that yields a total score.

\section{MetS definition}

MetS was defined according to the revised criteria of the ATEP III (National Cholesterol Education Program (NCEP) Expert Panel on Detection, Evaluation, and Treatment of High 
Blood Cholesterol in Adults (Adult Treatment Panel III), 2002), which requires the presence of 3 or more of the following 5 criteria: high waist circumference $(>94 \mathrm{~cm}$ for men and $>80$ $\mathrm{cm}$ for women), hypertriglyceridemia ( $\geq 1.7 \mathrm{mmol} / \mathrm{L}$ or on lipid-lowering medication), low HDL cholesterol level $(<1.03 \mathrm{mmol} / \mathrm{L}$ in men and $<1.29 \mathrm{mmol} / \mathrm{L}$ in women $)$, high blood pressure $(\geq 130 / 85 \mathrm{mmHg}$ or on antihypertensive medication), and high fasting glucose concentration ( $\geq 5.6 \mathrm{mmol} / \mathrm{L}$ or on glucose-lowering medication).

High sensitivity CRP (hs-CRP) was measured in blood samples and an abnormal level was defined as $>3 \mathrm{mg} / \mathrm{L}$ (Emerging Risk Factors Collaboration et al., 2010).

\section{Derived metabolic indices}

Abdominal obesity was defined by the presence of both hypertriglyceridemia $(\geq 1.7 \mathrm{mmol} / \mathrm{L}$ or current treatment by a triglyceride lowering medication) and high waist circumference (>94 $\mathrm{cm}$ for male and $>80 \mathrm{~cm}$ for females) (Després and Lemieux, 2006). Atherogenic index of plasma (AIP) which is considered as a very sensitive predictor of future cardiovascular events was defined as $\log$ (triglycerides/HDL cholesterol) (Zhu et al., 2015). Disposition Index (DI) quantifies the nature of the interactions between insulin sensitivity and pancreatic secretion. It is predictive of the development of type 2 diabetes. DI is estimated by the equation $\log (\mathrm{DI})=$ 2.449-0.113 $\times$ fasting plasma glucose + $0.046 \times$ BMI $-0.612 \times$ HDL cholesterol $($ Lin et al., 2014).

\section{Statistical analysis}

Categorical variables are expressed as numbers and percentages, and continuous variables as mean \pm Standard Deviation $(\mathrm{SD})$ values. Associations between childhood maltreatment and MetS or its subcomponents were performed using Mann-Witney U tests and analyses of variance. Effect sizes were estimated with Cohen's d. Unadjusted analyses and multivariable 
analyses adjusted for site of recruitment and level of education were performed. We then used several variables (age, sex, age at onset, type of $\mathrm{BD}$, illness duration, rapid cycling, current use of atypical antipsychotics) as moderators in the analyses, meaning that the associations between CTQ score and MetS were examined separately in each category of a given moderator (for example in females and then in males, when sex was the moderator). Unadjusted analyses and analyses adjusted for site of recruitment and level of education were performed.

Finally, we provided two logistic regression models to test for potential interactions between CTQ total score and moderators (identified in the previous analyses) and using MetS as the dependent variable. These models included the following independent variables: CTQ score, identified moderators and interactions between CTQ score and identified moderators, adjusted for site of recruitment and level of education (model 1), then further adjusted for other clinical variables in a second model (model 2). Statistical analyses were performed with SAS (release 9.4; SAS Statistical Institute, Cary, NC). All statistical tests were two-tailed.

\section{Results}

This study included a sample of 2390 individuals with BD. Overall, $49.5 \%$ of the individuals were diagnosed with BD type I, $40.7 \%$ with BD type II, and $9.9 \%$ with BD-NOS. The mean age at inclusion was $41.1( \pm 12.6), 60.5 \%$ were women, the mean age at onset was $24.0( \pm 9.6)$ years.

The prevalence of MetS was 22.1\%. The presence of MetS was associated with male $(\mathrm{p}<0.0001)$, older age $(\mathrm{p}<0.0001)$, lower education level $(\mathrm{p}=0.0002)$, site of recruitment $(p<0.0001)$, longer duration of the illness $(p<0.0001)$, older age at BD onset $(p<0.0001)$ and 
current use of atypical antipsychotics $(\mathrm{p}=0.0069)$ (see supplementary table 1 ), but not with BD subtypes or rapid cycling.

Table 1 shows the univariable associations between childhood maltreatment and MetS components. There was no major association between childhood maltreatment (CTQ total score) and MetS, nor with its subcomponents (hypertension, HDL cholesterol, triglycerides, high fasting glucose). An association was observed between a higher waist circumference and a higher CTQ total score $(\mathrm{p}=0.02)$, however the effect size was small and the association was no longer significant after adjustment for site of recruitment and level of education. After adjustment for site of recruitment and level of education, some associations were identified between a higher CTQ score, hypertriglyceridemia $(\mathrm{p}=0.03)$ and a higher AIP $(\mathrm{p}=0.05)$. The associations between the CTQ total score and other indices related to a higher cardio-vascular risk (abdominal obesity, body mass index, abnormal CRP, and DI) were not significant.

We then investigated the associations between CTQ total score and MetS while stratifying analyses on the following moderators: sex, age at inclusion below/above 40 years old, BD subtype, illness duration below/above 15 years, early/late age at onset of $\mathrm{BD}$, presence/absence of rapid cycling, current use of atypical antipsychotics) (see table 2). After adjustment for potential confounders (education level, site of recruitment, and age and/or sex when appropriate), we observed associations between childhood maltreatment and MetS in men and in individuals aged less than 40 years old. The associations between childhood maltreatment and MetS were not moderated by the other variables (age at onset, current treatment with atypical antipsychotics, rapid cycling, bipolar disorders subtype, and illness duration).

Finally, we performed two logistic regression models with MetS as the dependent variable and the following independent variables: CTQ total score, age, sex and age at onset and the interactions between these three variables and CTQ total score, with an adjustment for site of 
recruitment and level of education (model 1), and with further adjustment BD subtype, rapid cycling, and current use of antipsychotics (model 2). Model 1 identified an interaction between CTQ total score and sex on the risk of MetS $(\mathrm{p}=0.04)$, that was no longer significant when controlled for confounders in model $2(\mathrm{p}=0.34)$. Both models identified also associations between the risk of MetS and an older age $(\mathrm{p}<0.01)$, while model 2 further identified current atypical antipsychotics use as being associated with MetS ( $\mathrm{p}=0.02)$ (results not shown in details, available upon request from the authors).

\section{Discussion}

In a large sample of 2390 individuals with BD, we suggested associations between childhood maltreatment and MetS in men, in younger individuals and in individuals with an early onset of the disease. However, most moderation analyses were no longer significant after adjustment for potential confounders.

Association between body mass index or MetS and childhood adversities has previously been explored in the general population, although showing inconsistent results and small effect sizes (Suglia et al., 2018). In individuals with severe mental disorders, and particularly with BD, data are scarce and obtained in small sample sizes. A cross-sectional study (373 adults with major depressive disorder or BD) reported no significant association between childhood maltreatment and obesity after taking into account several potential confounders (McIntyre et al., 2012). A recent study including 271 patients with severe psychiatric disorders (including 123 individuals with BD) showed that childhood abuse was associated with an higher BMI (Aas et al., 2017). Contrary to these results, Leclerc et al., in a sample of 61 individuals with $\mathrm{BD}$, have reported an association between childhood sexual abuse and higher BMI, only in the subgroups of individuals with a late onset of BD (Leclerc et al., 2018). Given these 
inconsistent results, the links between childhood maltreatment and MetS in BD remain to be clarified.

Several mechanisms have been proposed to explain the association between childhood maltreatment and MetS in individuals with BD. First, many studies have demonstrated that childhood maltreatment may lead to a more severe form of $\mathrm{BD}$ that would require more psychotropics use and consequently more exposure to potential side effects leading to MetS. Second, associations between childhood maltreatment and tobacco, alcohol and drugs misuses, which are key risk factors for poor health outcomes, have been largely documented (Agnew-Blais and Danese, 2016). Third, childhood maltreatment has been suggested to modify gene expression and potential underlying epigenetic mechanisms, and is also associated with low grade inflammation (pro-inflammatory cytokines), known to be associated with MetS.

Our study has several strengths, including a large sample of individuals with BD, and a reliable diagnosis. However, because this work is cross-sectional, we cannot establish any causal links, and longitudinal studies are required for this purpose. In addition, even though childhood maltreatment was assessed using an accurate and validated instrument, it is a retrospective questionnaire, and its reliability may be hampered by recall bias.

Combining conflicting results in the literature and results from this study, we cannot support the hypothesis of a strong association between childhood maltreatment and MetS in BD. We suggest that this association may exist only in subgroups of individuals, i.e. in males, in younger individuals or in individuals with an early onset of the disease. However, site of recruitment, level of education and current use of atypical antipsychotics vanished the associations, thus raising some methodological concerns for future studies that should pay attention to these potential confounders. Given their high prevalence in individuals with BD, 
both MetS and childhood maltreatment should be systematically assessed. More research is needed to clarify the links between childhood maltreatment and cardio-vascular risk in individuals with $\mathrm{BD}$ and therefore to further define how psychosocial interventions that target childhood maltreatment and its consequences may be beneficial for physical health.

Number of words: 2005

Funding and sponsor: This research was supported by the Foundation FondaMental, the Institut National de la Santé et de la Recherche Médicale (INSERM), the Assistance Publique des Hôpitaux de Paris (AP-HP), and by the Investissements d'Avenir program managed by the Agence national pour la Recherche (ANR) under references ANR-11-IDEX-0004-02 and ANR-10-COHO-10-01. This funding source had no role in the study design, data collection, analysis, preparation of the manuscript, or decision to submit the manuscript for publication.

Acknowledgments: We thank the FondaMental Foundation (www-fondationfondamental.org) for scientific cooperation in mental health, which is developing a new model for translational research in psychiatry in France and supports the infrastructure of Centers of Expertise in BD. We express our thanks to the nurses, and to the patients who were included in the present study. We thank Hakim Laouamri, $\mathrm{PhD}^{1}$ and his team (Seif Ben Salem, Msc ${ }^{1}$, Karmène Souyris, $\mathrm{PhD}^{1}$, Victor Barteau, $\mathrm{Msc}^{1}$ and Mohamed Laaidi, $\mathrm{PhD}^{1}$ ) for the development of the FACE-BD computer interface, data management, quality control and regulatory aspects. 


\section{References}

Aas, M., Dieset, I., Hope, S., Hoseth, E., Mørch, R., Reponen, E., Steen, N.E., Laskemoen, J.F., Ueland, T., Aukrust, P., Agartz, I., Andreassen, O.A., Melle, I., 2017. Childhood maltreatment severity is associated with elevated C-reactive protein and body mass index in adults with schizophrenia and bipolar diagnoses. Brain. Behav. Immun. 65, 342-349. https://doi.org/10.1016/j.bbi.2017.06.005

Agnew-Blais, J., Danese, A., 2016. Childhood maltreatment and unfavourable clinical outcomes in bipolar disorder: a systematic review and meta-analysis. Lancet Psychiatry Apr;3(4):342-9.

American Psychiatric Association, 1994. American Psychiatric Association. Diagnostic and Statistical Manual of Mental Disorders, 4th edn. Washington, DC: American Psychiatric Association.

Bernstein, D.P., Stein, J.A., Newcomb, M.D., Walker, E., Pogge, D., Ahluvalia, T., Stokes, J., Handelsman, L., Medrano, M., Desmond, D., Zule, W., 2003. Development and validation of a brief screening version of the Childhood Trauma Questionnaire. Child Abuse Negl. 27, 169-190. https://doi.org/10.1016/s0145-2134(02)00541-0

Després, J.-P., Lemieux, I., 2006. Abdominal obesity and metabolic syndrome. Nature 444, 881-887. https://doi.org/10.1038/nature05488

Emerging Risk Factors Collaboration, Sarwar, N., Gao, P., Seshasai, S.R.K., Gobin, R., Kaptoge, S., Di Angelantonio, E., Ingelsson, E., Lawlor, D.A., Selvin, E., Stampfer, M., Stehouwer, C.D.A., Lewington, S., Pennells, L., Thompson, A., Sattar, N., White, I.R., Ray, K.K., Danesh, J., 2010. Diabetes mellitus, fasting blood glucose concentration, and risk of vascular disease: a collaborative meta-analysis of 102 prospective studies. Lancet Lond. Engl. 375, 2215-2222. https://doi.org/10.1016/S0140-6736(10)60484-9

First, M., 1996. Structured Clinical Interview for the DSM-IV Axis I Disorders. Am. Psychiatr. Assoc.

Henry, C., Etain, B., Godin, O., Dargel, A.A., Azorin, J.-M., Gard, S., Bellivier, F., Bougerol, T., Kahn, J.-P., Passerieux, C., Aubin, V., Courtet, P., Leboyer, M., FACE-BD group, 2015. Bipolar patients referred to specialized services of care: Not resistant but impaired by sub-syndromal symptoms. Results from the FACE-BD cohort. Aust. N. Z. J. Psychiatry 49, 898-905. https://doi.org/10.1177/0004867415585582

Hosang, G.M., Fisher, H.L., Hodgson, K., Maughan, B., Farmer, A.E., 2018. Childhood maltreatment and adult medical morbidity in mood disorders: comparison of unipolar depression with bipolar disorder. Br. J. Psychiatry J. Ment. Sci. 213, 645-653. https://doi.org/10.1192/bjp.2018.178

Hughes, K., Bellis, M.A., Hardcastle, K.A., Sethi, D., Butchart, A., Mikton, C., Jones, L., Dunne, M.P., 2017. The effect of multiple adverse childhood experiences on health: a systematic review and meta-analysis. Lancet Public Health 2, e356-e366. https://doi.org/10.1016/S2468-2667(17)30118-4

Leboyer, M., Soreca, I., Scott, J., Frye, M., Henry, C., Tamouza, R., Kupfer, D.J., 2012. Can bipolar disorder be viewed as a multi-system inflammatory disease? J. Affect. Disord. https://doi.org/10.1016/j.jad.2011.12.049

Leclerc, E., Mansur, R.B., Grassi-Oliveira, R., Cordeiro, Q., Kapczinski, F., McIntyre, R.S., Brietzke, E., 2018. The differential association between history of childhood sexual abuse and body mass index in early and late stages of bipolar disorder. J. Affect. Disord. 227, 214-218. https://doi.org/10.1016/j.jad.2017.10.031 
Lin, J.-D., Hseih, C.H., Liu, C.C., Lian, W.-C., Wu, C.-Z., Hsu, C.-H., Pei, D., Hsia, T.-L., Chen, Y.-L., 2014. Estimation of the disposition index based on components of metabolic syndrome. Endocr. J. 61, 789-796.

Management of Physical Health Conditions in Adults with Severe Mental Disorders, 2018. , WHO Guidelines Approved by the Guidelines Review Committee. World Health Organization, Geneva.

McIntyre, R.S., Soczynska, J.K., Liauw, S.S., Woldeyohannes, H.O., Brietzke, E., Nathanson, J., Alsuwaidan, M., Muzina, D.J., Taylor, V.H., Cha, D.S., Kennedy, S.H., 2012. The association between childhood adversity and components of metabolic syndrome in adults with mood disorders: results from the international mood disorders collaborative project. Int. J. Psychiatry Med. 43, 165-177. https://doi.org/10.2190/PM.43.2.e

National Cholesterol Education Program (NCEP) Expert Panel on Detection, Evaluation, and Treatment of High Blood Cholesterol in Adults (Adult Treatment Panel III), 2002.

Third Report of the National Cholesterol Education Program (NCEP) Expert Panel on Detection, Evaluation, and Treatment of High Blood Cholesterol in Adults (Adult Treatment Panel III) final report. Circulation 106, 3143-3421.

Quidé, Y., Tozzi, L., Corcoran, M., Cannon, D.M., Dauvermann, M.R., 2020. The Impact of Childhood Trauma on Developing Bipolar Disorder: Current Understanding and Ensuring Continued Progress. Neuropsychiatr. Dis. Treat. 16, 3095-3115. https://doi.org/10.2147/NDT.S285540

Roshanaei-Moghaddam, B., Katon, W., 2009. Premature mortality from general medical illnesses among persons with bipolar disorder: a review. Psychiatr. Serv. Wash. DC 60, 147-156. https://doi.org/10.1176/appi.ps.60.2.147

Suglia, S.F., Koenen, K.C., Boynton-Jarrett, R., Chan, P.S., Clark, C.J., Danese, A., Faith, M.S., Goldstein, B.I., Hayman, L.L., Isasi, C.R., Pratt, C.A., Slopen, N., Sumner, J.A., Turer, A., Turer, C.B., Zachariah, J.P., American Heart Association Council on Epidemiology and Prevention; Council on Cardiovascular Disease in the Young; Council on Functional Genomics and Translational Biology; Council on Cardiovascular and Stroke Nursing; and Council on Quality of Care and Outcomes Research, 2018. Childhood and Adolescent Adversity and Cardiometabolic Outcomes: A Scientific Statement From the American Heart Association. Circulation 137, e15e28. https://doi.org/10.1161/CIR.0000000000000536

Vancampfort, D., Stubbs, B., Mitchell, A.J., De Hert, M., Wampers, M., Ward, P.B., Rosenbaum, S., Correll, C.U., 2015. Risk of metabolic syndrome and its components in people with schizophrenia and related psychotic disorders, bipolar disorder and major depressive disorder: a systematic review and meta-analysis. World Psychiatry Off. J. World Psychiatr. Assoc. WPA 14, 339-347. https://doi.org/10.1002/wps.20252

Zhu, X.-W., Deng, F.-Y., Lei, S.-F., 2015. Meta-analysis of Atherogenic Index of Plasma and other lipid parameters in relation to risk of type 2 diabetes mellitus. Prim. Care Diabetes 9, 60-67. https://doi.org/10.1016/j.pcd.2014.03.007 
Table 1: Association between metabolic syndrome (and its components) and childhood maltreatment

\begin{tabular}{|c|c|c|c|c|c|c|c|}
\hline & $\mathrm{n}$ & $\begin{array}{c}\text { Childhood } \\
\text { Maltreatment } \\
\text { Mean CTQ } \\
\text { score (sd) } \\
\end{array}$ & ES & $\begin{array}{l}\text { Chi- } \\
\text { Square/ } \\
\text { F value }\end{array}$ & DF & $\begin{array}{c}\mathrm{P} \\
\text { value }\end{array}$ & $\begin{array}{c}\mathrm{P} \\
\text { value }^{* *}\end{array}$ \\
\hline $\begin{array}{l}\text { Metabolic syndrome } \\
\text { No } \\
\text { Yes }\end{array}$ & $\begin{array}{c}1862 \\
528\end{array}$ & $\begin{array}{l}42.6(14.3) \\
43.2(15.2)\end{array}$ & 0.04 & 0.28 & 1 & 0.59 & 0.29 \\
\hline $\begin{array}{l}\text { High blood pressure } \\
\text { No } \\
\text { Yes }\end{array}$ & $\begin{array}{c}1620 \\
914 \\
\end{array}$ & $\begin{array}{l}43.1(14.6) \\
42.2(14.1) \\
\end{array}$ & 0.06 & 1.76 & 1 & 0.18 & 0.33 \\
\hline $\begin{array}{l}\text { Low HDL cholesterol or treatment } \\
\text { No } \\
\text { Yes }\end{array}$ & $\begin{array}{c}1556 \\
669\end{array}$ & $\begin{array}{l}42.6(14.4) \\
43.1(15.0)\end{array}$ & 0.03 & 0.55 & 1 & 0.45 & 0.57 \\
\hline $\begin{array}{l}\text { Hypertriglyceridemia } \\
\text { No } \\
\text { Yes }\end{array}$ & $\begin{array}{c}1864 \\
527\end{array}$ & $\begin{array}{l}42.6(14.4) \\
43.2(14.5)\end{array}$ & 0.04 & 1.29 & 1 & 0.25 & 0.03 \\
\hline $\begin{array}{l}\text { High Fasting glucose } \\
\text { No } \\
\text { Yes }\end{array}$ & $\begin{array}{c}1932 \\
351\end{array}$ & $\begin{array}{l}42.8(14.6) \\
42.2(13.7) \\
\end{array}$ & 0.04 & 0.12 & 1 & 0.72 & 0.17 \\
\hline $\begin{array}{l}\text { High waist circumference } \\
\text { No } \\
\text { Yes }\end{array}$ & $\begin{array}{r}896 \\
1613 \\
\end{array}$ & $\begin{array}{l}42.1(14.4) \\
43.3(14.6) \\
\end{array}$ & 0.08 & 5.74 & 1 & 0.02 & 0.99 \\
\hline $\begin{array}{l}\text { Abdominal obesity } \\
\text { No } \\
\text { Yes }\end{array}$ & $\begin{array}{l}706 \\
404 \\
\end{array}$ & $\begin{array}{l}42.1(14.6) \\
43.6(15.0) \\
\end{array}$ & 0.10 & 3.41 & 1 & 0.06 & 0.06 \\
\hline $\begin{array}{l}\text { Body Mass Index } \\
<25 \\
25-30 \\
>30\end{array}$ & $\begin{array}{l}1342 \\
841 \\
482\end{array}$ & $\begin{array}{l}42.7(14.7) \\
42.2(13.7) \\
44.2(15.2)\end{array}$ & $\begin{array}{l}0.03 \\
0.10\end{array}$ & 2.95 & 2 & 0.05 & 0.13 \\
\hline $\begin{array}{l}\text { AIP }\left(>75^{\text {th }}\right) \\
\text { No } \\
\text { Yes }\end{array}$ & $\begin{array}{c}1777 \\
593\end{array}$ & $\begin{array}{l}42.7(14.5) \\
42.8(14.5)\end{array}$ & 0.007 & 0.19 & 1 & 0.66 & 0.05 \\
\hline $\begin{array}{l}\text { DI }\left(>75^{\text {th }}\right) \\
\text { No } \\
\text { Yes }\end{array}$ & $\begin{array}{c}1680 \\
559\end{array}$ & $\begin{array}{l}42.9(14.6) \\
42.5(14.2)\end{array}$ & 0.03 & 0.08 & 1 & 0.78 & 0.54 \\
\hline $\begin{array}{l}\text { Abnormal CRP } \\
\text { No } \\
\text { Yes }\end{array}$ & $\begin{array}{c}1342 \\
513 \\
\end{array}$ & $\begin{array}{l}42.1(14.5) \\
43.4(14.7) \\
\end{array}$ & 0.09 & 3.36 & 1 & 0.07 & 0.61 \\
\hline
\end{tabular}

*Mann-Whitney U test for the associations between childhood trauma (total score) and dichotomous variables

Multivariable analysis of covariance adjusted for age, sex, number of education level and site of recruitment.

CTQ: Childhood Trauma Questionnaire; MetS: Metabolic Syndrome, Abdominal obesity: defined as having high waist circumference and hypertriglyceridemia; AIP: Atherogenic 
index of plasma; DI: Disposition Index, HDL High Density Lipoprotein; Abnormal CRP level: defined as > $3 \mathrm{mg} / \mathrm{L}$; ES: Effect Size; DF: Degree of freedom 
Table 2: Univariable and multivariable associations between metabolic syndrome and childhood maltreatment according to moderators

\begin{tabular}{|c|c|c|c|c|c|c|c|c|}
\hline & \multicolumn{4}{|c|}{ Metabolic syndrome } & \multirow[b]{3}{*}{$\begin{array}{c}\text { Chi- } \\
\text { square }\end{array}$} & \multirow[b]{3}{*}{$P$ value } & \multirow[b]{3}{*}{ F value } & \multirow[b]{3}{*}{$\mathrm{P}$ value } \\
\hline & \multicolumn{2}{|r|}{ No } & \multicolumn{2}{|c|}{ Yes } & & & & \\
\hline & $\mathrm{n}$ & $\begin{array}{c}\text { CTQ } \\
\text { Mean (sd) }\end{array}$ & $\mathrm{n}$ & $\begin{array}{c}\text { CTQ } \\
\text { mean }(\mathrm{sd})\end{array}$ & & & & \\
\hline Male & 672 & $39.5(11.6)$ & 273 & $41.6(13.1)$ & 5.17 & 0.02 & 6.48 & $0.011^{a}$ \\
\hline Female & 1189 & $44.3(15.3)$ & 255 & $44.9(17.0)$ & 0.01 & 0.91 & & \\
\hline Age $<40$ & 1021 & $40.9(13.6)$ & 155 & $44.1(16.2)$ & 4.30 & 0.03 & 6.01 & $0.014^{b}$ \\
\hline Age $>40$ & 841 & $44.6(14.8)$ & 373 & $42.8(14.7)$ & 5.29 & 0.02 & 0.30 & $0.584^{\mathrm{b}}$ \\
\hline BD type I & 848 & $41.2(14.0)$ & 262 & $42.6(14.5)$ & 2.57 & 0.10 & & \\
\hline BD type II & 803 & $44.1(14.8)$ & 210 & $44.4(16.6)$ & 0.16 & 0.68 & & \\
\hline Illness duration $<15 y$ & 951 & $39.9(12.0)$ & 185 & $40.0(11.5)$ & 0.65 & 0.42 & & \\
\hline Illness duration $>15 y$ & 834 & $45.3(15.8)$ & 322 & $44.7(16.2)$ & 0.87 & 0.34 & & \\
\hline Early onset (<21y) & 903 & $43.0(14.9)$ & 195 & $45.8(16.5)$ & 4.32 & 0.03 & 2.46 & $0.116{ }^{c}$ \\
\hline Late onset & 885 & $41.9(13.6)$ & 312 & $41.3(13.4)$ & 0.23 & 0.62 & & \\
\hline Rapid cycling Yes & 1366 & $41.7(13.6)$ & 369 & $42.1(13.7)$ & 0.42 & 0.51 & & \\
\hline Rapid cycling No & 264 & $45.0(16.6)$ & 84 & $47.5(21.0)$ & 0.08 & 0.78 & & \\
\hline Antipsychotic medication Yes & 320 & $41.3(13.8)$ & 124 & $41.8(14.3)$ & 0.09 & 0.75 & & \\
\hline Antipsychotic medication No & 1283 & $42.7(14.5)$ & 298 & $43.6(15.5)$ & 0.65 & 0.42 & & \\
\hline
\end{tabular}

*Mann-Whitney U test for each moderator

**** Multivariable analysis of covariance for each moderator

a) adjustment for age, education level and site of recruitment

b) adjustment for sex, education level and site of recruitment

c) adjustment for age, sex, education level and site of recruitment

CTQ: Childhood Trauma Questionnaire, BD: Bipolar Disorder, y: years 
Supplementary Table: Factors associated with metabolic syndrome in individuals with bipolar disorders

\section{Metabolic syndrome}

\begin{tabular}{|c|c|c|c|}
\hline & $\begin{array}{c}\text { No } \\
(n=1862,77.9 \%)\end{array}$ & $\begin{array}{c}\text { Yes } \\
(\mathrm{n}=\mathbf{5 2 8}, \mathbf{2 2 . 1 \%})\end{array}$ & $P$ value \\
\hline \multicolumn{4}{|l|}{ Sex } \\
\hline Female & $1189(63.9)$ & $255(48.3)$ & $<0.0001$ \\
\hline Male & $672(36.1)$ & $273(51.7)$ & \\
\hline Age, mean (sd) & $39.4(12.3)$ & $47.0(12.0)$ & $<0.0001$ \\
\hline$<40$ & $1021(54.8)$ & $155(29.4)$ & $<0.0001$ \\
\hline$>40$ & $841(45.2)$ & $373(70.6)$ & \\
\hline Education level, mean (sd) & $14.2(2.8)$ & $13.6(3.4)$ & 0.0002 \\
\hline \multicolumn{4}{|l|}{ Site recruitment } \\
\hline Bordeaux & $57(74.0)$ & $20(26.0)$ & $<0.0001$ \\
\hline Grenoble & $248(79.0)$ & $71(22.0)$ & \\
\hline Marseille & $255(82.0)$ & $47(18.2)$ & \\
\hline Monaco & $212(81.9)$ & $9(14.3)$ & \\
\hline Montpellier & $54(85.7)$ & 79 (19.4) & \\
\hline Nancy & $329(80.6)$ & $94(36.4)$ & \\
\hline Ile de France & $795(79.3)$ & 208 (20.7) & \\
\hline \multicolumn{4}{|l|}{ BD subtype } \\
\hline BDI & $848(45.5)$ & $262(49.6)$ & 0.2518 \\
\hline BDII & $803(43.1)$ & $210(39.8)$ & \\
\hline BDNOS & $211(11.3)$ & $56(10.6)$ & \\
\hline Illness duration, mean (sd) & $16.0(10.5)$ & 20.7 (11.7) & $<0.0001$ \\
\hline$<15 \mathrm{y}$ & $951(53.3)$ & $185(36.5)$ & $<0.0001$ \\
\hline$>15 y$ & $834(46.7)$ & $322(63.5)$ & \\
\hline Age at onset, mean (sd) & $23.4(9.3)$ & $26.2(10.3)$ & $<0.0001$ \\
\hline Early onset & $885(49.5)$ & $312(61.5)$ & $<0.0001$ \\
\hline Late onset & $903(50.5)$ & $195(38.5)$ & \\
\hline \multicolumn{4}{|l|}{ Rapid cycling } \\
\hline No & $1366(83.8)$ & $369(81.5)$ & 0.2362 \\
\hline Yes & $264(16.2)$ & $84(18.5)$ & \\
\hline \multicolumn{4}{|l|}{ Antipsychotic medication } \\
\hline No & $1075(77.1)$ & 298 (70.6) & 0.0069 \\
\hline Yes & $320(22.9)$ & $124(29.4)$ & \\
\hline
\end{tabular}

